\title{
A mutation in the serine protease TMPRSS4 in a novel pediatric neurodegenerative disorder
}

\author{
Piya Lahiry ${ }^{1,2}$, Lemuel Racacho ${ }^{3}$, Jian Wang ${ }^{1}$, John F Robinson ${ }^{1}$, Gregory B Gloor ${ }^{4}$, C Anthony Rupar ${ }^{4,5}$, \\ Victoria M Siu', Dennis E Bulman ${ }^{3}$ and Robert A Hegele ${ }^{1,4,6^{*}}$
}

\begin{abstract}
Background: To elucidate the genetic basis of a novel neurodegenerative disorder in an Old Order Amish pedigree by combining homozygosity mapping with exome sequencing.

Methods and results: We identified four individuals with an autosomal recessive condition affecting the central nervous system (CNS). Neuroimaging studies identified progressive global CNS tissue loss presenting early in life, associated with microcephaly, seizures, and psychomotor retardation; based on this, we named the condition Autosomal Recessive Cerebral Atrophy (ARCA). Using two unbiased genetic approaches, homozygosity mapping and exome sequencing, we narrowed the candidate region to chromosome $11 \mathrm{q}$ and identified the C.995C > T (p.Thr332Met) mutation in the TMPRSS4 gene. Sanger sequencing of additional relatives confirmed that the c.995C > T genotype segregates with the ARCA phenotype. Residue Thr332 is conserved across species and among various ethnic groups. The mutation is predicted to be deleterious, most likely due to a protein structure alteration as demonstrated with protein modelling.

Conclusions: This novel disease is the first to demonstrate a neurological role for a transmembrane serine proteases family member. This study demonstrates a proof-of-concept whereby combining exome sequencing with homozygosity mapping can find the genetic cause of a rare disease and acquire better understanding of a poorly described protein in human development.
\end{abstract}

Keywords: Autosomal recessive cerebral atrophy (ARCA) syndrome, Neurodegeneration, Trypsin-like serine protease, Homozygosity, Microarray, Exome sequencing, Autosomal recessive inheritance, Old Order Amish

\section{Background}

Neurodegenerative disorders can be defined as disorders with progressive deterioration of neurological functions such as loss of vision, hearing, and motor function along with previously attained skills [1]. Such degeneration is frequently associated with seizures, feeding issues and intellectual impairment. Neurodegenerative disorders can be etiologically classified under acquired and inherited causes [1]. Acquired causes are most common, and include chronic viral infections, toxin deposition such as heavy metal ingestion and cancer chemotherapy, and drug metabolites [2]. Inherited causes can be due to specific genetic and metabolic defects, such as Rett syndrome,

\footnotetext{
* Correspondence: hegele@robarts.ca

'Robarts Research Institute, London, ON, Canada

${ }^{4}$ Department of Biochemistry, Schulich School of Medicine and Dentistry, University of Western Ontario, London, ON, Canada

Full list of author information is available at the end of the article
}

mitochondrial disorders such as MELAS, toxin-generating defects such as PKU, Wilson disease and HallervordenSpatz syndrome, lysosomal storage diseases such as Niemann-Pick (types A and C) and Gaucher disease, and leukodystrophies such as Alexander disease [2].

Neurodegeneration in these disorders can involve both the grey and white matter of the brain and spinal cord. Injury of grey matter is irreversible and manifests as seizures, psychomotor retardation, visual impairment and extrapyramidal disturbances such as akathisia (inability to remain motionless) [2]. On the other hand whitematter, mainly represented by myelinated axons, involves disease that is dominated by motor difficulties and chronic encephalopathy [2].

Herein we describe a novel neurodegenerative disorder affecting four infants in a highly consanguineous Amish pedigree. Using homozygosity mapping and exome sequencing, we identified a mutation in TMPRSS4, a

\section{Biomed Central}


transmembrane serine protease, whose physiological role is poorly understood. This work exemplifies the use of unbiased approaches to find novel proteins implicated in rare single-gene disorders.

\section{Materials and methods}

This study had ethics approval by the Office of Research Ethics at the University of Western Ontario (number 07920E). Four participating families from an Old Order Amish community in Ontario provided informed consent and received no financial compensation. All four probands had thorough clinical evaluations, including MRI-head scans. In addition, an autopsy of one proband (V-9) was completed. The pedigrees of the families were assembled through interviews and local Amish community records. In addition, DNA from umbilical cord blood and buccal swabs were extracted from 208 ARCAunaffected individuals from the Old Order Amish community to determine mutant allele frequency.

Genomic DNA of peripheral blood from 3 affected $(\mathrm{V}-10, \mathrm{~V}-12, \mathrm{~V}-14)$ and 5 unaffected $(\mathrm{V}-6, \mathrm{~V}-8, \mathrm{IV}-8$, $\mathrm{V}-15$, IV-12) parents and siblings were genotyped using Genome-Wide Human SNP Array 6.0 at London Regional Genomics Centre (http://www.Irgc.ca). Genotypes were called using Affymetrix Genotyping Console, with quality control thresholds for subject call rate (>90\%), SNP call rate (95\%), Hardy-Weinberg equilibrium $(\mathrm{P}>0.0001)$ and minor allele frequency $(>1 \%)$. Due to the consanguineous nature of the pedigree, family-based autozygosity or homozygosity mapping was performed using Agilent GT v2.0 software to scan the genotyped SNPs for runs of homozygous blocks. The location scores for each of these homozygous blocks were calculated within Agilent GT v2.0. While a few homozygous block were seen, the one on chromosome 11q clearly had the highest location score and this block was considered to most likely harbour the disease gene [3].

For exome sequencing, targeted enrichment and sequencing were performed on DNA extracted from the peripheral blood of individuals $\mathrm{V}-10$ and $\mathrm{V}-12$, both with typical features of ARCA. Exome enrichment was performed with Agilent SureSelect Human All Exon $50 \mathrm{MB}$ Kit at The Centre for Applied Genomics (http:// www.tcag.ca). Paired-end sequencing was performed on Illumina GAII generating 100-bp reads, which were subsequently aligned to the human reference genome sequence (hg19/ GRCh37), using NextGENe software and CLC-Bio Workbench.

TMPRSS4 in the linked region on chromosome $11 \mathrm{q}$ was first screened by Sanger sequencing in an affected individual, a parent, an unaffected sibling, and a nonAmish control. Co-segregation of the TMPRSS4 variation with disease was demonstrated with direct sequence analysis in a total of 18 family members, including the affected individuals. TaqMan assays were used for identifying allele frequency of the TMPRSS4 variation in exon 10, c.995C > T (GI:145701031), within 208 Old Order Amish controls and 2382 ethnically diverse and healthy non-Amish controls. TaqMan quantitative realtime PCR assays provided allele discrimination using two allele-specific TaqMan probes synthesized for detecting the TMPRSS4 variation (allele C: 5' VIC-CTG CTT CGT AAA GCC and mutant allele A: 5' FAMCTG CTT CAT AAA GCC).

Conservation of the TMPRSS4 protein across species was determined with ClustalW, a multiple-sequencealignment computer program [4]. Impact of the amino acid mutation on TMPRSS4 protein structure, function, and pathological implication was predicted with four online tools, namely PolyPhen-2, Panther, SNPs3D, and PMUT.

\section{Results}

\section{Clinical characterization of autosomal recessive cerebral} atrophy (ARCA)

Four affected children were identified in an Old Order Amish pedigree (Figure 1) to have similar clinical features and subsequently a thorough clinical evaluation was performed on them (Table 1).

$\mathrm{V}-9$, born in 2004, was the product of an uncomplicated pregnancy and delivery at 36.5 weeks gestation, with a head circumference of $30 \mathrm{~cm}\left(<3^{\text {rd }}\right.$ percentile). Her neonatal period was unremarkable until 6 weeks of age, when the infant refused to suck. By 3 months of age, she had frequent reflux, was agitated during feeds and was generally irritable. By 7 months of age, she had regressed such that she was unable to smile or laugh, to rollover or sit-up unsupported, and could neither 'babble' nor 'coo'. Growth charts demonstrated progressive microcephaly with head circumference at $<3{ }^{\text {rd }}$ percentile at 6.5 months of age. Musculoskeletal examinations demonstrated spasticity (fisted hands and leg scissoring), abnormal tone and constant akathisia with no notable seizure activity. Visual impairment was suggested since she was unable to follow objects by 1 year of age. Investigations ruled out known inborn errors of metabolism and mitochondrial disorders. Of note she had abnormal blood work of unknown significance demonstrating elevated ammonia, manganese, lactate, and platelets levels. MRI and CT scans revealed severe diffuse loss of cerebral volume with symmetrical enlargement of ventricular space, affected grey and white matter with a thinned corpus callosum, however, the cerebellum, brainstem and midbrain were spared. Eventually, she was placed in palliative care since she was unable to swallow or drink independently. She died at 18 months most likely due to failure to thrive, with no follow-up autopsy. 


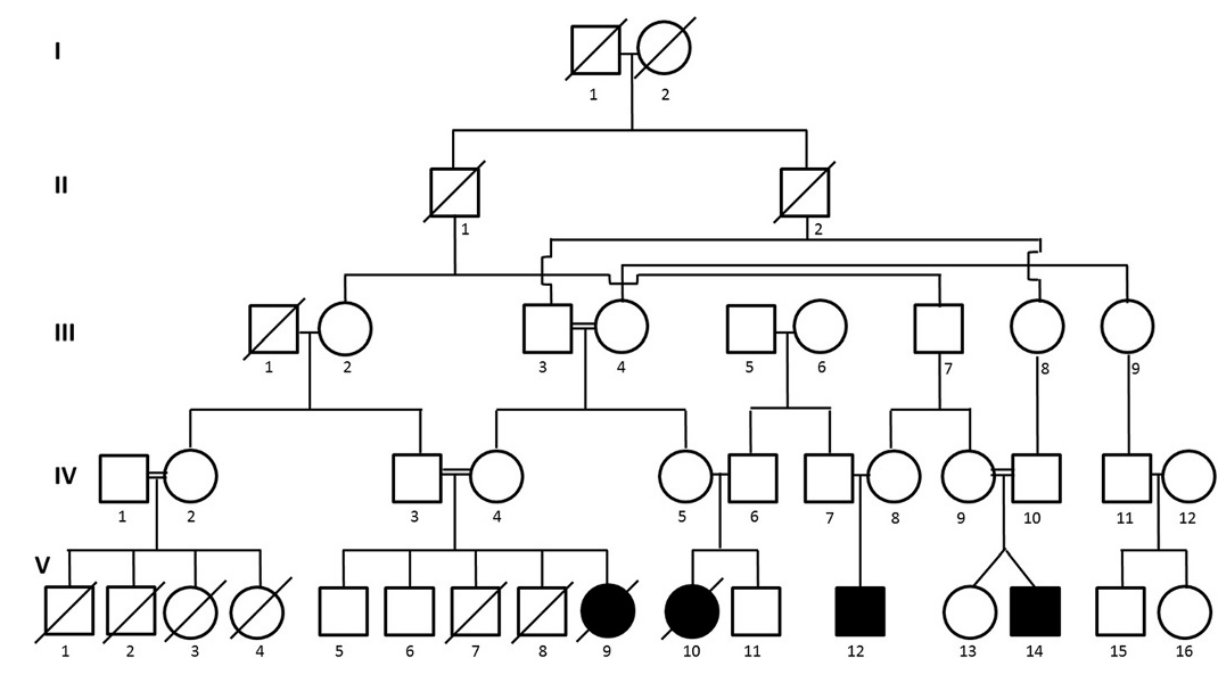

Figure 1 Old Order Amish pedigree with consanguinity (indicated by the double lines) has four individuals with ARCA, a disease with an autosomal-recessive mode of inheritance. Affected individuals are shown as blackened squares (male) and circles (female). Diagonal lines across symbols indicate deceased individuals.

V-10 was born in 2000 at gestational age of 38 weeks following a normal pregnancy and delivery. Once again, the infant was developing appropriately until 3 months of age when she stopped gaining weight, stopped smiling, was unable to 'coo' nor roll over. Suckling regressed by 5 months of age and she had a G-tube insertion by one year of age. Her family doctor noted microcephaly with no head growth post 6 weeks of birth and premature anterior fontanelle closure. At 2 years of age, her head circumference was recorded at $35.5 \mathrm{~cm}\left(<3^{\text {rd }}\right.$ percentile). By 6 months of age she developed seizures described to cause head deviation, ipsilateral arm extension, lip biting and a high-pitched scream followed by a brief period of sleep and then arousal. Interestingly, EEG performed at 9 months demonstrated no epileptiform activity. These seizure-like episodes increased in frequency by 15 months of age such that she was placed on a palliative seizure therapy regimen. She also had arm stiffness and leg scissoring indicating spasticity, akathisia, brisk reflexes and hypotonic lower extremities. In addition, she was irritable and startled easily. Investigations ruled out MELAS, inborn errors of metabolism and Hallervorden-Spatz syndrome, and muscle biopsies were normal. MRI demonstrated enlarged lateral and $3^{\text {rd }}$ ventricles with marked atrophy of cortical tissue, sparing the pons and cerebellum (Figure 2A). The infant died at 2 years of age. Although autopsy was unable to prove cause of death, it was concluded that the seizures were not severe enough to cause cortical degeneration. Gross evaluation of brain revealed a pale thalami, normal occipital region, brainstem, and cerebellum as well as symmetrical atrophy of cerebral hemispheres. Microscopic evaluation of the brain demonstrated unaffected brain stem and meninges, material deposition in neurons, like calcium, as well as severe loss of myelin in white matter. The rest of the organs were unremarkable on autopsy.

$\mathrm{V}-12$ was born at 39 weeks gestation in 2001 following an uncomplicated pregnancy and delivery. He had a relatively unremarkable neonatal period except that his parents noted him to have constant akathisia only while awake. He was microcephalic since 3 months of age and was recorded to have a premature anterior fontanelle closure with a head circumference measurement of $43.3 \mathrm{~cm}$ at 4 years of age $\left(<3^{\text {rd }}\right.$ percentile). Regression of developmental milestones began within 1 month of age when he stopped smiling, had exaggerated startle response by 3 months; at 4.5 years he was able to kick some toys and bat at objects, but could neither speak nor gesture. He had a diagnosis of cortical visual impairment with atrophic optic fundi and nystagmus by 2 years of age. By 3 months of age, he began having episodes of repetitive extension of arms and hands associated with stiffening of the body with a shriek-like cry with EEG findings of generalized epileptiform activity. By 4 years of age, he was prescribed monthly botox injections and daily oral baclofen, and was wheelchair bound due to the spasms and abnormal increased muscle tone, which began by 11 months of age. He also had a G-tube insertion to prevent his recurrent aspiration pneumonitis episodes. Investigations ruled out known inborn errors of metabolism and MELAS. Blood work demonstrated elevated manganese, lactate, and platelet levels. Imaging consistently showed cerebral atrophy and ventriculomegaly with subtle atrophy of brainstem and corpus callosum. At 12 years of age, he continues to live 
Table 1 Clinical description of the four ARCA-affected individuals

\begin{tabular}{|c|c|c|c|c|c|}
\hline & & \multicolumn{4}{|c|}{ Affected individuals (year of birth) } \\
\hline & & V-9 (2004) & V-10 (2000) & V-12 (2001) & V-14 (1999) \\
\hline \multicolumn{2}{|l|}{ Karyotype } & $46, X X$ & $46, X X$ & $46, X Y$ & $46, X Y$ \\
\hline \multicolumn{2}{|l|}{$\begin{array}{l}\text { Pregnancy } \\
\text { and delivery }\end{array}$} & Uncomplicated & Uncomplicated & Uncomplicated & $\begin{array}{l}\text { Clomid- } \\
\text { induced but } \\
\text { uncomplicated }\end{array}$ \\
\hline \multicolumn{2}{|l|}{$\begin{array}{l}\text { GA at } \\
\text { delivery }\end{array}$} & 36.5 weeks & 38 weeks & 39 weeks & 39 weeks \\
\hline \multicolumn{2}{|l|}{$\begin{array}{l}\text { Weight at } \\
\text { birth }\end{array}$} & 2455 g (10th percentile) & $2610 \mathrm{~g}$ (10th percentile) & N/A & $\begin{array}{l}2550 \mathrm{~g}(<3 \mathrm{rd} \\
\text { percentile) }\end{array}$ \\
\hline \multicolumn{2}{|l|}{$\begin{array}{l}\text { Length at } \\
\text { birth }\end{array}$} & $47.5 \mathrm{~cm}$ (25th percentile) & N/A & N/A & $\mathrm{N} / \mathrm{A}$ \\
\hline \multicolumn{2}{|l|}{$\mathrm{HC}$, at birth ${ }^{*}$} & $30 \mathrm{~cm}$ (<3rd percentile) & N/A & N/A & N/A \\
\hline \multicolumn{2}{|l|}{$\begin{array}{l}\text { Fontanelle } \\
\text { closure }\end{array}$} & $\begin{array}{l}\text { at } 6.5 \text { mo: Anterior open }(\mathrm{N}) \text {, } \\
\text { posterior closed }(\mathrm{N})\end{array}$ & at 2 mo: Anterior closed (abN) & $\begin{array}{l}\text { at } 5.5 \text { mo: Anterior closed } \\
\text { (abN) }\end{array}$ & $\begin{array}{l}\text { at } 8 \text { mo: } \\
\text { Anterior } \\
\text { fontanelle } \\
\text { closed }\end{array}$ \\
\hline \multicolumn{2}{|l|}{ Status } & died at 18 months & died at 2 years & alive at $12 \mathrm{yrs}$ & alive at 14 yrs \\
\hline \multicolumn{2}{|l|}{ Autopsy } & - & + & - & - \\
\hline \multirow{4}{*}{$\begin{array}{l}\text { Development } \\
\text { milestones }\end{array}$} & Suckling & stopped by 6 weeks & stopped by 5 mo & N/A & N/A \\
\hline & Smile & $\begin{array}{l}\text { started at } 2 \text { mo, stopped by } \\
7 \text { mo }\end{array}$ & Started at $2 \mathrm{mo}$, stopped by $3 \mathrm{mo}$ & no reflexive smile at $1 \mathrm{mo}$ & $\begin{array}{l}\text { Started at } 2 \\
\text { mo, stopped } \\
\text { by } 4 \text { mo }\end{array}$ \\
\hline & Sitting & unable at $7 \mathrm{mo}$ & unable at $8 \mathrm{mo}$ & unable at 4 yrs & unable at 5 yrs \\
\hline & Babbling & unable at $7 \mathrm{mo}$ & unable at $8 \mathrm{mo}$ & no speech at $4 \mathrm{yr}$ & N/A \\
\hline \multirow[t]{9}{*}{$\begin{array}{l}\text { Neurological } \\
\text { signs }\end{array}$} & $\begin{array}{l}\text { Seizures/ } \\
\text { Epilepsy }\end{array}$ & - & + & + & + \\
\hline & EEG & N/A & $\begin{array}{l}\text { marked abnormality with low } \\
\text { cortical activity, no epileptiform } \\
\text { activity noted }\end{array}$ & $\begin{array}{l}\text { generalized central } \\
\text { epileptiform activity }\end{array}$ & $\begin{array}{l}\text { Grade } 1 \\
\text { generalized } \\
\text { and } \\
\text { suppressed } \\
\text { cerebral } \\
\text { activity }\end{array}$ \\
\hline & Spasticity & + (fisted hands, legs scissoring) & + (legs scissoring, arms stiff) & $\begin{array}{l}+ \text { (myoclonic spasm due } \\
\text { to sound/light touch, fisted } \\
\text { hands) }\end{array}$ & $\begin{array}{l}+ \text { (clonus of } \mathrm{R} \\
\text { ankle) }\end{array}$ \\
\hline & Reflexes & N/A & brisk, clonus of $L$ ankle & unable to assess & hyperreflexia \\
\hline & Tone & $\begin{array}{l}\text { hypotonic trunk, hypertonic } \\
\text { extremities }\end{array}$ & Hypotonic lower extremities & $\begin{array}{l}\text { hypotonic trunk, } \\
\text { hypertonic extremities }\end{array}$ & $\begin{array}{l}\text { hypertonic } \\
\text { extremities }\end{array}$ \\
\hline & Irritable & ++ & ++ & +++ & +++ \\
\hline & $\begin{array}{l}\text { Head } \\
\text { circumference, } \\
\text { last recorded }\end{array}$ & $\begin{array}{l}36.5 \mathrm{~cm} @ 6.5 \mathrm{mo}(<3 \mathrm{rd} \\
\text { percentile) }\end{array}$ & 35.5 cm @ 2 yrs (<3rd percentile) & $\begin{array}{l}43.3 \mathrm{~cm} @ 4 \text { yrs (<3rd } \\
\text { percentile) }\end{array}$ & $\begin{array}{l}39 \mathrm{~cm} \text { at } 8.5 \\
\text { mo (<3rd } \\
\text { percentile) }\end{array}$ \\
\hline & Akathisia & + & + & ++ (while awake) & ++ \\
\hline & Startles & easily & easily & $\begin{array}{l}\text { easily however less } \\
\text { pronounced presently }\end{array}$ & $\begin{array}{l}\text { easily however } \\
\text { less } \\
\text { pronounced } \\
\text { presently }\end{array}$ \\
\hline \multirow[t]{2}{*}{$\begin{array}{l}\text { Vision and } \\
\text { Hearing }\end{array}$} & $\begin{array}{l}\text { Visual } \\
\text { impairment }\end{array}$ & inconsistent with cues & infrequent, strabismus & $\begin{array}{l}\text { cortical, horizontal + } \\
\text { vertical nystagmus }\end{array}$ & $\begin{array}{l}\text { cortical visual } \\
\text { impairment, } \\
\text { eyes roll back }\end{array}$ \\
\hline & Fundoscopy & N/A & N/A & mild atrophic fundi & $\begin{array}{l}\text { hypoplastic } \\
\text { optic nerve } \\
\text { and fovea }\end{array}$ \\
\hline
\end{tabular}


Table 1 Clinical description of the four ARCA-affected individuals (Continued)

\begin{tabular}{|c|c|c|c|c|c|}
\hline & Hearing & Normal & normal & normal & normal \\
\hline Other organs & G-tube & - & at $1 \mathrm{yr}$ & $\begin{array}{l}\text { at } 4 \text { yrs due to recurrent } \\
\text { aspiration pneumonitis }\end{array}$ & - \\
\hline $\begin{array}{l}\text { Abnormal } \\
\text { Bloodwork }\end{array}$ & & $\begin{array}{l}\text { Elevated ammonia, Mn, lactate, } \\
\text { platelets }\end{array}$ & & $\begin{array}{l}\text { Elevated Mn, lactate, and } \\
\text { platelets }\end{array}$ & $\begin{array}{l}\text { Elevated CK, } \\
\text { CK-MB, and } \\
\text { platelets }\end{array}$ \\
\hline \multirow[t]{2}{*}{ MRI } & $\begin{array}{l}\text { Age at time of } \\
\text { imaging }\end{array}$ & $10 \mathrm{mo}$ & $8 \mathrm{mo}, 11 \mathrm{mo}$ & $3 \mathrm{mo}, 12 \mathrm{mo}$ & $\begin{array}{l}7 \mathrm{mo}, 13 \mathrm{mo}, \\
6 \mathrm{yrs} 7 \mathrm{mo}\end{array}$ \\
\hline & Description & $\begin{array}{l}\text { Severe symmetrical cerebral } \\
\text { volume loss, gray and white } \\
\text { matter affected, thinned corpus } \\
\text { callosum. Cerebellum, } \\
\text { brainstem, midbrain and } \\
\text { supratentorial deep grey matter } \\
\text { are unaffected. }\end{array}$ & $\begin{array}{l}\text { Enlarged lateral and 3rd ventricles, } \\
\text { severe uniform atrophy of the } \\
\text { brain with subcortical white matter } \\
\text { loss. Normal spine to T2, } \\
\text { cerebellum and pons. }\end{array}$ & $\begin{array}{l}\text { Marked progressive } \\
\text { cerebral and cerebellar } \\
\text { atrophy with basal ganglia } \\
\text { involvement }\end{array}$ & $\begin{array}{l}\text { Prominent } \\
\text { ventricles, thin } \\
\text { white and } \\
\text { grey matter }\end{array}$ \\
\hline \multirow[t]{2}{*}{ CT } & $\begin{array}{l}\text { Age at time of } \\
\text { imaging }\end{array}$ & $6 \mathrm{mo}$ & & $3 \mathrm{mo}$ & \\
\hline & Description & $\begin{array}{l}\text { Prominent subarachnoid spaces } \\
\text { and ventricular system. } \\
\text { Infratentorial compartment is } \\
\text { normal, including cerebellum } \\
\text { and 4th ventricle }\end{array}$ & & $\begin{array}{l}\text { Generalized cerebral } \\
\text { atrophy with associated } \\
\text { ventriculomegaly, difficult } \\
\text { to differentiate between } \\
\text { grey/white matter }\end{array}$ & \\
\hline
\end{tabular}

* Based on: Barbier et al, 2013. Pediatrics. "New Reference curves for Head Circumference at Birth, by GA". Abbreviations: N/A, not available; "-", not determined.

with his family and is fully dependent on others, however his seizures are better controlled seizures and he is less irritable.

V-14 was the first known proband with ARCA in this pedigree born in 1999. He was a product of a clomidinduced twin pregnancy with a fraternal sister who continues to have normal development. Delivery was induced at 39 weeks with a birth weight of 2550 grams $\left(<3^{\text {rd }}\right.$ percentile). His neonatal period was unremarkable overall. He was microcephalic prior to development regressions, which were first noted after 4 months of age. By 4 months he stopped smiling, laughing, cooing, and had abnormal tone. By 9 months of age, he would be easily startled, irritable, and agitated while feeding. By 5 years, he could only hold his head up, was severely spastic, had hyperreflexive extremities, and was unable to eat solid foods. By 3 years of age he was diagnosed with visual impairment due to cortical abnormalities, with hypoplastic optic nerve and fovea. Investigations demonstrated no lysosomal, peroxisomal or metabolic disorders. EEG demonstrated supressed Grade 1 cerebral activity with generalized abnormal cortical activity. MRI of spine demonstrated no abnormalities; however, ventricles and sulci were prominent in size and severely atrophic white and gray matter (Figure 2B). He is presently 14 years old and continues with generalized spasticity and requires a pureed diet, which he regularly chokes on. He is less irritable and on no medications.

Overall, all four children were products of an unremarkable pregnancy, delivery and neonatal period. However, acquired microcephaly was noted within 2 months of birth. By 4 months of age, the infants displayed constant irritability, regression of developmental milestones, akathisia, increased startle response, spasticity, abnormal tone, visual impairment and seizures. In two of the four children, the anterior fontanelle had prematurely closed. Brain imaging of all four affected children revealed a characteristic ventriculomegaly and progressive symmetrical atrophy of brain matter-in particular the white and grey matter of the cortex, sparing the infratentorial segments, such as the midbrain, brainstem and cerebellum.

Based on the clinical findings and imaging, we named this novel disorder as Autosomal Recessive Cerebral Atrophy (ARCA).

\section{Molecular investigations}

Exome sequencing was performed on 2 affected individuals (V-10 and V-12) and a filtering method was applied to identify unique nucleotide variants, which yielded 42 and 77 novel homozygous sequence variants in individuals V-10 and V-12, respectively (Figure 3A). Homozygosity mapping revealed a candidate region, the homozygous block with the highest location score (Figure 3B), encompassing $4.5 \mathrm{Mbp}$ in chromosome 11q with a location score of 303 comprising of 872 SNPs and 91 genes (Figure 3B). Within this candidate region in chromosome 11, only 1 of the unique nucleotide variants was present in homozygous state in both affected individuals while their parents were obligate heterozygotes. The variant is a $\mathrm{C}$ to $\mathrm{T}$ at c.995 in exon 10 of the TMPRSS4 gene, resulting in an amino acid change from threonine $(\mathrm{T})$ to methionine $(\mathrm{M})$ at residue $332(\mathrm{~T} 332 \mathrm{M}$, 


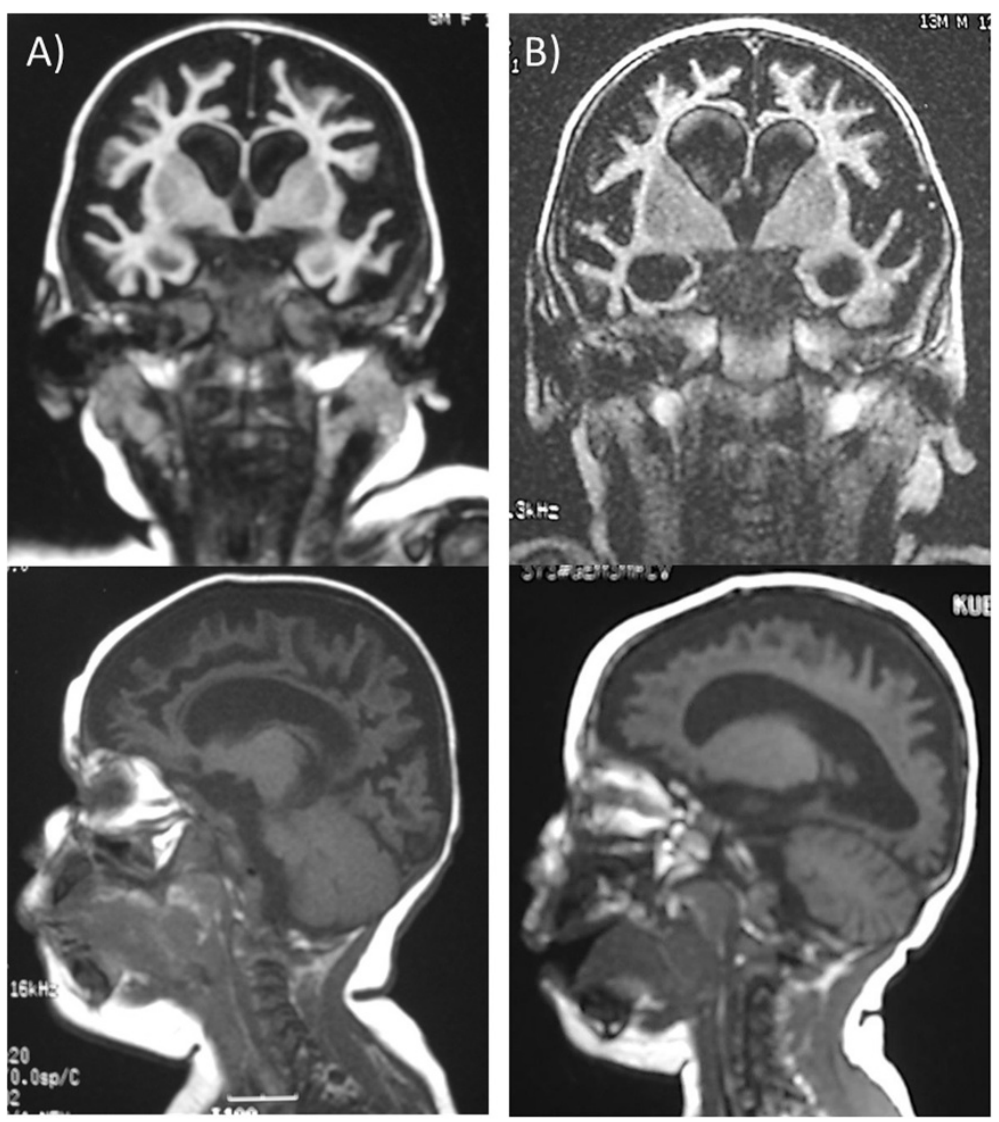

Figure 2 Coronal and sagittal views of T1-weighted MRI-head of ARCA patients demonstrating diffuse cortical atrophy and ventriculomegaly. A) $\mathrm{V}-10$ at 8 months of age, B) $\mathrm{V}-14$ at 10 months of age.

Figure 4). Sanger sequencing of TMPRSS4 c.995C > T in the pedigree is consistent with an autosomal recessive inheritance pattern, and segregates with the ARCA phenotype (see Additional file 1). The frequency of the $\mathrm{T}$ allele was assessed within 208 Old Order Amish community members (excluding the pedigree). None had the TT genotype while $12 \%$ had the CT genotype (carrier rate); thus 1 in 250 Old Order Amish are predicted to have the TT genotype. In 2382 geographically and ethnically diverse controls, all had the CC genotype suggesting that the TT genotype is a private mutation within this Old Order Amish community.

\section{In silico investigations}

To better understand the biological significance of this mutation, various bioinformatics strategies were employed. Residue 332 is within the trypsin-like serine protease domain (Figure 5A). The ClustalW protein sequence alignment program showed strong conservation of this residue among TMPRSS4 orthologs from other organisms (Figure 5B). PolyPhen, Panther and SNPs3D, similarly showed that the $T$ to $M$ change at residue 332 would be deleterious or damaging to TMPRSS4 function.
The crystal structure of TMPRSS4 has yet to be published and there is no related structure with an identity $>40 \%$. However, examination of the domain structure of TMPRSS4 shows that the C-terminal half of the protein is an excellent match (E-value of 3.1e-91) to the trypsin-like serine protease family (cd00190) [5]. Alignment of the TMPRSS4 sequence with the available structures of this family, using the Cn3D tool [6], demonstrate that residue 332 is in a conserved loop that borders the active site. In majority of these homologous structures, the residue side chain is partially exposed on the surface and in one structure (1MKX) the side chain is directed into the active site. In either case, the T332M change-a polar to a non-polar amino acid coupled with a longer side chain-would likely result in a steric clash that could lead to substrate binding alteration and thus altered TMPRSS4 function.

\section{Discussion and conclusion}

We describe a novel pediatric disorder in an Old Order Amish community, named Autosomal Recessive Cerebral Atrophy (ARCA) due to a progressive brain atrophy leading to neurodegenerative symptoms 


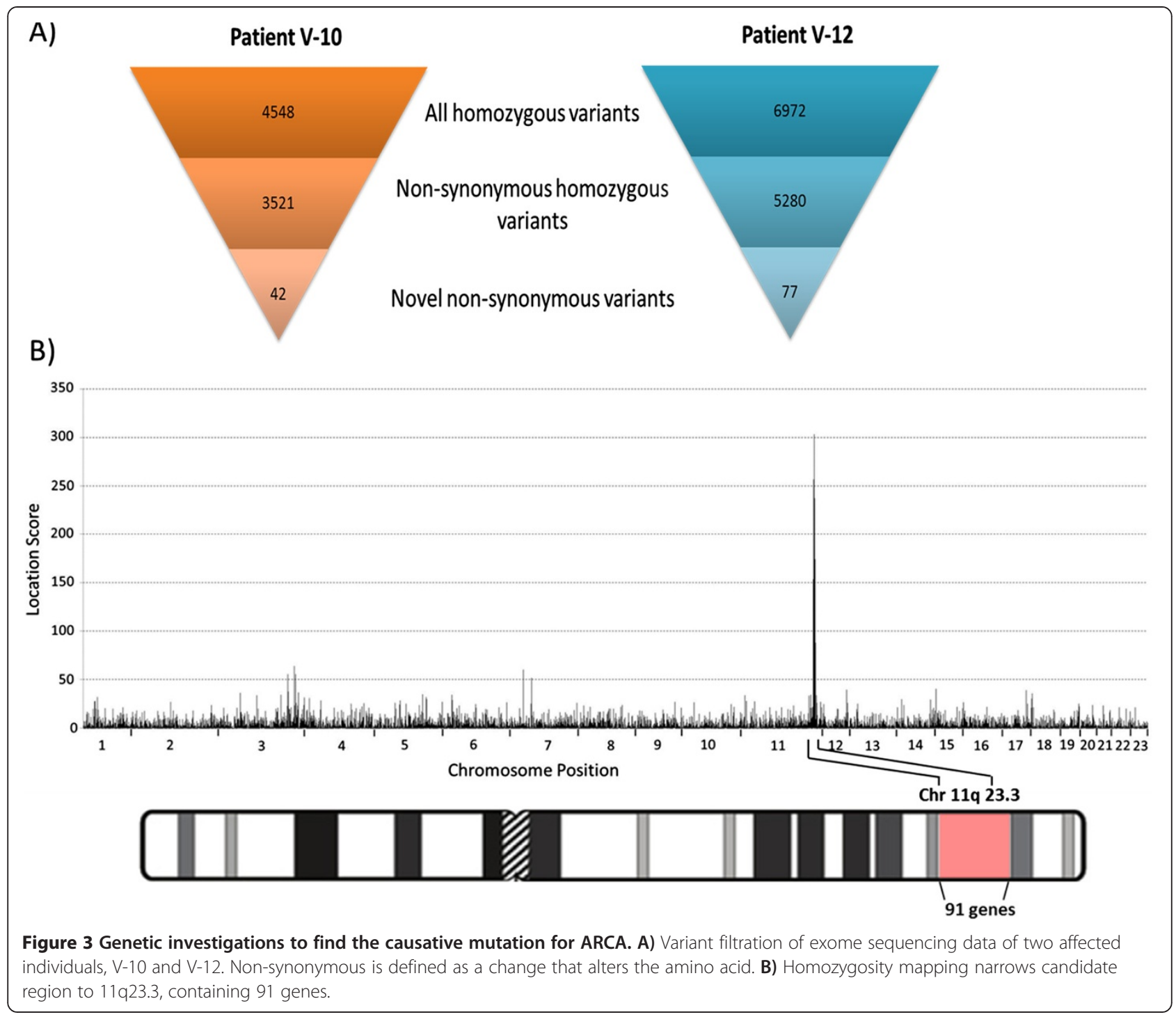

including loss of developmental milestones, seizures and loss of motor function.

Although there was slight variability in the age of developmental milestone regression, by 4 months of age all 4 infants displayed irritability, akathisia, increased startle response, abnormal reflex and tone, visual impairment, as well as seizures or seizure-like episodes. In addition, the infants were noted to have microcephaly early in life and brain imaging revealed a characteristic ventriculomegaly and progressive symmetrical atrophy of brain matter, particularly cortical white and grey matter. Even though the degenerative process of the brain matter most likely started earlier in development, the infants may have been asymptomatic perinatally or during the neonatal stage, since the cerebrum is functionally silent during the early weeks of life [7]. It is likely that 2 of the 4 children continue to survive due to the level of medical intervention provided by the caregivers rather than biological variability in the severity of the disease.

After conducting a comprehensive literature search of the clinical descriptions of ARCA, we identified three similar yet distinct syndromes. For instance, patients with micropthalmia, brain atrophy (MOBA; MIM: 611222), develop extensive atrophy of white and grey matter after 6 months of life leading to progressive spasticity and seizures. However, unlike ARCA, MOBA patients also have congenital ocular malformations [8]. A case report, in 2011, describes two Japanese sisters with failure of postnatal brain growth with similar brain MRI findings to those of ARCA-affected patients. However, these sisters also had dysmorphic facial features and simplified gyri that were not present in ARCA [9]. Furthermore, West syndrome or Early Infantile Epileptic Encephalopathy 5 (EIEE5, MIM: 613477) is 


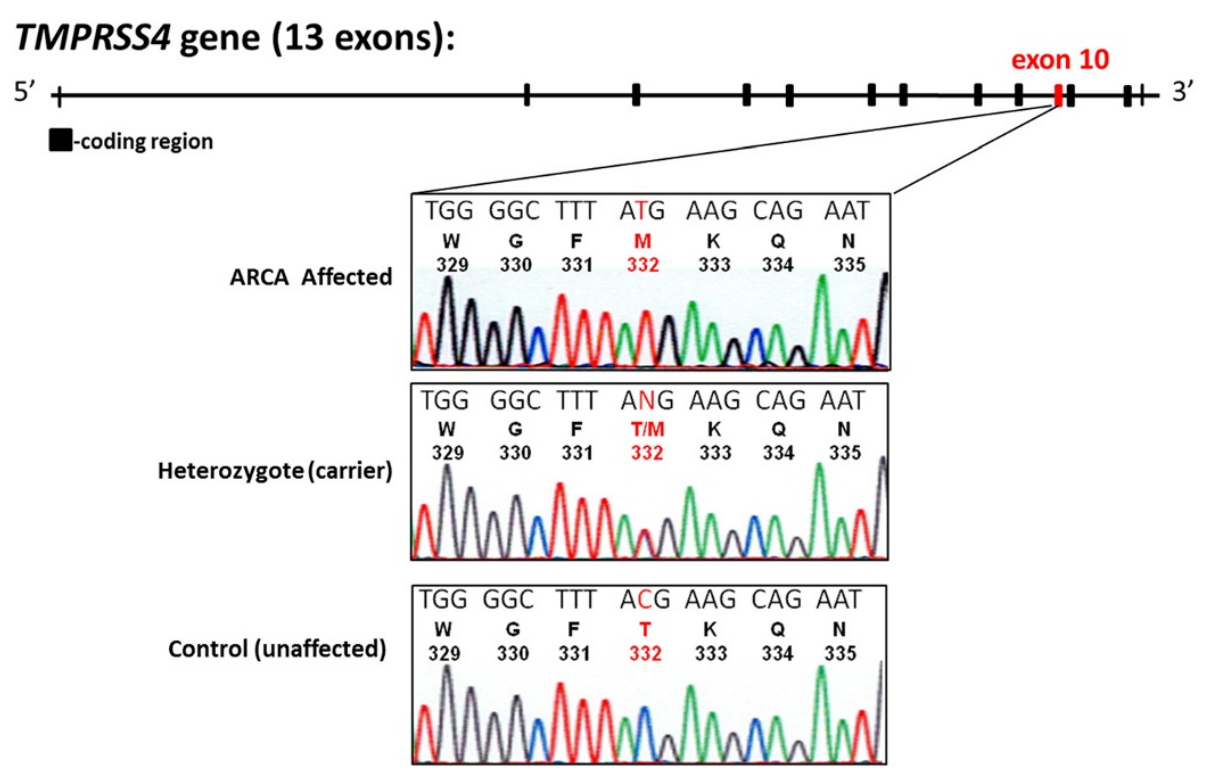

Figure 4 The genomic structure of TMPRSS4 gene consists of 13 coding exons with a nucleotide change in exon 10 (indicated in red) that alters threonine to methionine at residue 332 (T332M). DNA sequence tracings of TMPRSS4 exon 10 in an ARCA affected (top), T332M heterozygote (middle), and an unaffected (bottom) individual. For each tracing, the nucleotide sequence is shown at the top followed by the single-letter amino acid code and codon numbers beneath.

similar to ARCA in that the seizures manifest around 3 months of age due to brain atrophy [10]. However this atrophy is mostly localized to the brainstem due to hypomyelination of white matter in this region. EIEE5 is due to a heterozygous mutation in SPTAN1 gene encoding spectrin, a cytoskeletal protein involved in scaffolding [11].
Using exome sequencing and homozygosity mapping we identified a homozygous missense (T332M) mutation in the serine protease, TMPRSS4. This mutation segregated with the disease and no carriers were found outside of the Amish community, giving genotypic and statistical evidence that the TMPRSS4 mutation is likely causative of ARCA. Bioinformatics further illustrated that

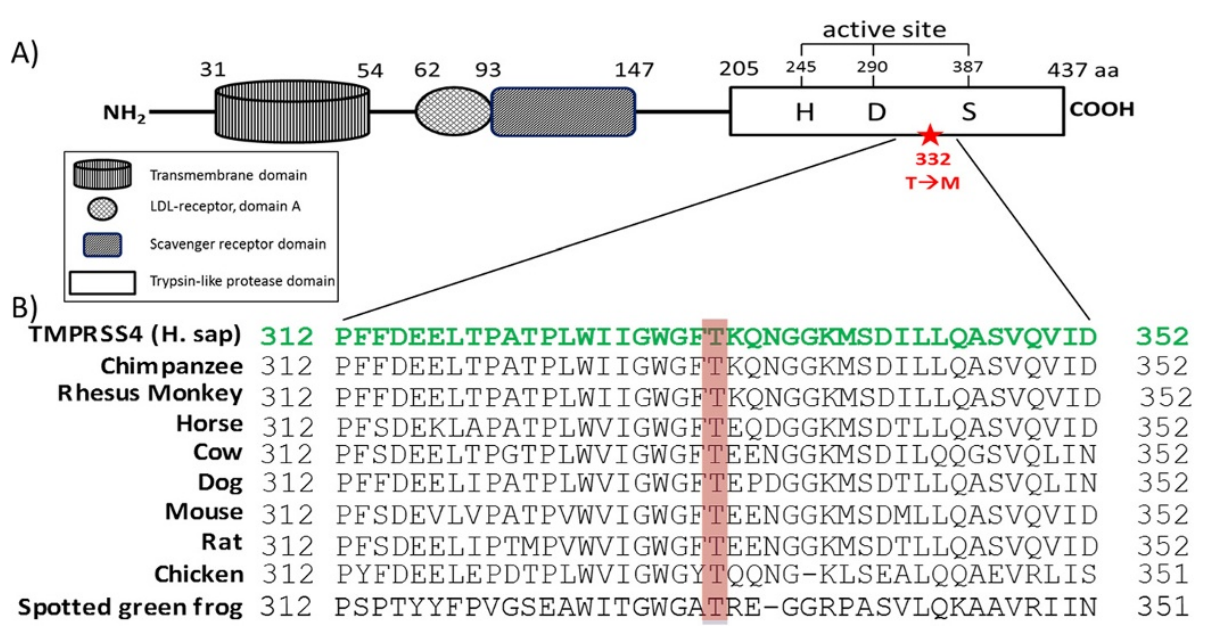

Figure 5 TMPRSS4 protein structure and amino acid sequence alignment with its orthologs. A) A schematic representation of TMPRSS4 protein domain structure. At the N-terminal the protein has a transmembrane domain, a LDL-receptor A domain, and a scavenger receptor domain. The C-terminal encodes for the trypsin-like serine protease domain which contains the catalytic triad amino acids (histidine, aspartic acid, serine). The T332 residue (indicated with a red star) is also found within this domain. B) Multiple alignments (using ClustalW) demonstrate that T332 residue (highlighted in red) is highly conserved across a representative set of species-specific TMPRSS4 orthologs. 
this $\mathrm{T}$ to $\mathrm{M}$ mutation at residue 332 , most likely affects protein function due to: 1 ) high evolutionary conservation of the residue, 2) program predictions that demonstrate pathological consequence, and 3) predicted changes in protein structure leading to instability.

Serine proteases, such as trypsin-like proteases are ubiquitously distributed and play pivotal roles in the gastrointestinal, reproductive, and immune systems [12]. Trypsin-like serine-proteases have been implicated in brain plasticity, neural development, neurodegeneration and neuroregeneration through human disorders and knock-out zebra fish models [13]. Specifically, one of the first serine proteases shown to be involved in human non-syndromic mental retardation was neurotrypsin [14]. Of note, the family members of Type II transmembrane serine proteases (TMPRSSs), TMPRSS2, TMPRSS1, TMPRSS3, and TMPRSS5 have only been implicated in certain types of sensorineural deafness [15]. TMPRSS4 is expressed in the gastrointestinal tract, skeletal muscle and brain. It is highly expressed on the cell surface of pancreatic, thyroid, lung, and other cancer tissues, with potential biological implication in cell invasion and migration [16].

This study demonstrates that TMPRSS4 is strongly implicated in the causation of this autosomal recessively inherited pediatric neurological disease. This information can now be used for genetic counselling in the community and to stimulate mechanistic research on this protein and mutation.

\section{Additional file}

Additional file 1: Figure of the pedigree illustrating ARCA phenotype along with genotype data Figure legend (description)Sanger sequencing of TMPRSS4 C.995C > T in the pedigree is consistent with an autosomal recessive inheritance pattern and segregates with the ARCA phenotype. The top half of each symbol indicates whether the individual is ARCA affected (black) or unaffected (white). The bottom half of the symbol represents the genotype with T shown in black and $\mathrm{C}$ shown in white.

\section{Abbreviations}

ARCA: Autosomal recessive cerebral atrophy; TMPRSS4: Transmembrane protease, serine 4; SNP: Single nucleotide polymorphism; Gtube: Gastrostomy tube; MELAS: Mitochondrial encephalomyopathy, lactic acidosis, and stroke-like episodes; EEG: Electroencephalogram.

\section{Competing interests}

The authors declare that they have no competing interests.

\section{Authors' contributions}

$\mathrm{PL}$ and RAH were involved in design, acquisition and analysis of data, and drafting of the manuscript. JW and JR were in involved acquisition and analysis of data.LR, GBG, CAR, VMS, and DEB were involved in design, acquisition and analysis of data, and made contributions to the draft of the manuscript.

\section{Acknowledgements}

We acknowledge the generous cooperation of the families participating in this study. We acknowledge the excellent technical assistance of Henian Cao and Roger Dewar. R.A.H. is a Career Investigator of the Heart and Stroke Foundation of Ontario and holds the Edith Schulich Vinet Canada Research Chair (Tier I) in Human Genetics and the Jacob J. Wolfe Distinguished Medical Research Chair. P.L. was supported by the Canadian Institutes of Health Research (CIHR) Scriver Family MD/PhD studentship award. This work was supported by a team grant from the CIHR (CTP-79853, MOP-37854), the Heart and Stroke Foundation of Ontario, Genome Canada through the Ontario Genomics Institute, and grants from the Children's Health Research Institute, the Lawson Health Research Institute, and the Garrod Association.

\section{Author details}

${ }^{1}$ Robarts Research Institute, London, ON, Canada. ${ }^{2}$ Department of Pediatrics, The Hospital for Sick Children, Toronto, ON, Canada. ${ }^{3}$ Departments of Pediatrics, Biochemistry, Microbiology and Immunology, University of Ottawa and Children's Hospital of Eastern Ontario Research Institute, Ottawa, ON, Canada. ${ }^{4}$ Department of Biochemistry, Schulich School of Medicine and Dentistry, University of Western Ontario, London, ON, Canada. ${ }^{5}$ Department of Pediatrics and Children's Health Research Institute, Lawson Health Research Institute, London, ON, Canada. ${ }^{6}$ Blackburn Cardiovascular Genetics Laboratory, Robarts Research Institute, 100 Perth Drive, Room 406, London, ON N6A 5K8, Canada.

Received: 14 June 2013 Accepted: 16 August 2013

Published: 17 August 2013

\section{References}

1. Rama-Devi R: Regression of milestones: neurodegenerative in 1st national conference on neurogenetics. Pediatric Oncall 2006. [serial online] 2007 [cited 15 February 2007(Supplement 2)]; 4. Available from: http: //www.pediatriconcall.com/fordoctor/Conference_abstracts/ NEUROGENETICSDEL/Approach.asp

2. Hardiman O, Doherty CP: Neurodegenerative Disorders: A Clinical Guide. London: Springer; 2011.

3. Puffenberger EG, Hu-Lince D, Parod JM, Craig DW, Dobrin SE, Conway AR, Donarum EA, Strauss KA, Dunckley T, Cardenas JF, et al: Mapping of sudden infant death with dysgenesis of the testes syndrome (SIDDT) by a SNP genome scan and identification of TSPYL loss of function. Proc Natl Acad Sci U S A 2004, 101:11689-11694.

4. Thompson JD, Higgins DG, Gibson TJ: CLUSTAL W: improving the sensitivity of progressive multiple sequence alignment through sequence weighting, position-specific gap penalties and weight matrix choice. Nucleic Acids Res 1994, 22:4673-4680.

5. Marchler-Bauer A, Lu S, Anderson JB, Chitsaz F, Derbyshire MK, DeWeese-Scott C, Fong JH, Geer LY, Geer RC, Gonzales NR, et al: CDD: a conserved domain database for the functional annotation of proteins. Nucleic Acids Res 2011, 39:D225-D229.

6. Wang Y, Geer LY, Chappey C, Kans JA, Bryant SH: Cn3D: sequence and structure views for Entrez. Trends Biochem Sci 2000, 25:300-302.

7. Verma UL, Archbald F, Tejani NA, Handwerker SM: Cerebral function monitor in the neonate. I: normal patterns. Dev Med Child Neurol 1984, 26:154-161.

8. Kanavin OJ, Haakonsen M, Server A, Bajwa TJ, van der Knaap MS, Stromme P: Microphthalmia and brain atrophy: a novel neurodegenerative disease. Ann Neurol 2006, 59:719-723.

9. Hirose M, Haginoya K, Yokoyama H, Kikuchi A, Hino-Fukuyo N, Munakata M, Uematsu M, linuma K, Kato M, Yamamoto T, Tsuchiya S: Progressive atrophy of the cerebrum in 2 Japanese sisters with microcephaly with simplified gyri and enlarged extraaxial space. Neuropediatrics 2011, 42:163-166.

10. Tohyama J, Akasaka N, Osaka H, Maegaki Y, Kato M, Saito N, Yamashita S, Ohno K: Early onset West syndrome with cerebral hypomyelination and reduced cerebral white matter. Brain Dev 2008, 30:349-355.

11. Saitsu H, Tohyama J, Kumada T, Egawa K, Hamada K, Okada I, Mizuguchi T, Osaka H, Miyata R, Furukawa T, et al: Dominant-negative mutations in alpha-II spectrin cause West syndrome with severe cerebral hypomyelination, spastic quadriplegia, and developmental delay. Am J Hum Genet 2010, 86:881-891.

12. Yousef GM, Kopolovic AD, Elliott MB, Diamandis EP: Genomic overview of serine proteases. Biochem Biophys Res Commun 2003, 305:28-36.

13. Wang Y, Luo W, Reiser G: Trypsin and trypsin-like proteases in the brain: proteolysis and cellular functions. Cell Mol Life Sci 2008, 65:237-252. 
14. Molinari F, Rio M, Meskenaite V, Encha-Razavi F, Auge J, Bacq D, Briault S, Vekemans M, Munnich A, Attie-Bitach T, et al: Truncating neurotrypsin mutation in autosomal recessive nonsyndromic mental retardation. Science 2002, 298:1779-1781.

15. Guipponi M, Toh MY, Tan J, Park D, Hanson K, Ballana E, Kwong D, Cannon PZ, Wu Q, Gout A, et al: An integrated genetic and functional analysis of the role of type II transmembrane serine proteases (TMPRSSs) in hearing loss. Hum Mutat 2008, 29:130-141.

16. Liang $B$, Wu M, Bu Y, Zhao A, Xie F: Prognostic value of TMPRSS4 expression in patients with breast cancer. Med Oncol 2013, 30:497.

doi:10.1186/1750-1172-8-126

Cite this article as: Lahiry et al:: A mutation in the serine protease TMPRSS4 in a novel pediatric neurodegenerative disorder. Orphanet Journal of Rare Diseases 2013 8:126.

\section{Submit your next manuscript to BioMed Central and take full advantage of:}

- Convenient online submission

- Thorough peer review

- No space constraints or color figure charges

- Immediate publication on acceptance

- Inclusion in PubMed, CAS, Scopus and Google Scholar

- Research which is freely available for redistribution 